\title{
PEDAGOGIA WALDORF: BASES EPISTEMOLÓGICAS DE UMA EDUCAÇÃO POTENCIALMENTE SALUTOGÊNICA
}

\begin{abstract}
Elaine Marasca ${ }^{1}$
RESUMO: Este estudo de revisão parte da premissa de que o exercício de Saúde implica em Educação, abrangendo a complexidade que a noção exige. $O$ objetivo é apresentar algumas das bases epistemológicas da Pedagogia Waldorf como proposta de uma educação salutogênica. A coerência desse sistema de ensino, apontando para o respeito ao ritmo de desenvolvimento integral que, nesta concepção abrange corpo, alma e espírito, pressupõe a construção de uma ordem interna, que enseja uma apropriação equilibrada de tempos e movimentos. Estimulando Pensar, Sentir e Querer igualitariamente, esse ensino concorre para a sustentação de um fluxo vital harmônico, potencialmente promotor de Saúde.
\end{abstract}

Palavras-chave: Pedagogia Waldorf. Salutogênese. Antroposofia. Educação. Promoção de Saúde.

\section{WALDORF PEDAGOGY: EPISTEMOLOGICAL BASES OF A POTENTIALLY SALUTOGENIC EDUCATION}

\begin{abstract}
This review study starts from the premise that the exercise of Health implies Education, embracing the complexity that the notion demands. The objective is to present some of the epistemological bases of Waldorf Pedagogy as a proposal for a salutogenic education. The coherence of this teaching system, pointing to respect for the rhythm of an integral development that, in this conception encompasses body, soul and spirit, presupposes the construction of an internal order, which leads to a balanced appropriation of times and movements. Stimulating Thinking, Feeling and Wanting equally, this teaching contributes to the sustaining of a harmonic vital flow, potentially health promoter.
\end{abstract}

Keywords: Waldorf Pedagogy. Salutogenesis. Anthroposophy. Education. Health promotion. 


\section{PEDAGOGÍA WALDORF: BASES EPISTEMOLÓGICAS DE UNA EDUCACIÓN POTENCIALMENTE SALUTOGÉNICA}

RESUMEN: Este estudio de revisión parte de la premisa de que el ejercicio de Salud implica en Educación, abarcando la complejidad que la noción exige. El objetivo es presentar algunas de las bases epistemológicas de la Pedagogía Waldorf como propuesta de una educación salutogénica. La coherencia de este sistema de enseñanza, apuntando al respeto al ritmo de un desarrollo integral que, en esta concepción abarca cuerpo, alma y espíritu, presupone la construcción de un orden interno, que permite una apropiación equilibrada de tiempos y movimientos. Estimulando Pensar, Sentir y Querer igualitariamente, esa enseñanza concurre para la sustentación de un flujo vital armónico, potencialmente promotor de Salud.

Palabras clave: Pedagogía Waldorf. Salutogénesis. Antroposofía. Educación. Promoción de la salud.

Saúde e Educação, no contexto mundial atual, apresentam desafios e necessidades semelhantes, especialmente quando se aponta para o desenvolvimento sustentável, para a globalização do processo econômico e, principalmente, para o desenvolvimento de uma ética do saber e do amor ao próximo (ANTUNES; PERDICARIS, 2010). Como já disse Minayo (1994), a saúde pode ser considerada um fenômeno clínico e sociológico vivido culturalmente, no qual, acredita-se, a educação se insere com papel fundamental. Esse estudo pretende incorporar ao conhecimento já consolidado sobre as questões de vida saudável, outros subsídios como, por exemplo, a possibilidade de essa conquista se dar por meio da educação formal.

Com base nessa realidade, pretende-se sugerir um sistema de ensino que realize sua práxis integrando corpo, alma e espírito; Pensar, Sentir e Querer igualitariamente; que respeite o ritmo de desenvolvimento da criança e valorize a arte como bastião de criatividade e que, dentre outros, se possa criar uma base para pavimentar um caminho para a saúde, congruente com o conceito de Salutogênese proposto por Antonovsky (1997). Esse novo conceito de saúde tem por premissa indagar sobre a origem da saúde e entender como o organismo, estimulado adequadamente, aprende a encontrar suas próprias forças para se manter saudável, apesar de vivenciar situações estressoras.

As pesquisas de Antonovsky (1979) se baseiam na pergunta base da Salutogênese: o que mantém as pessoas saudáveis? Essa é uma indagação exatamente oposta ao paradigma biomédico dominante - a Patogênese -, no qual todas as questões têm origem na doença. $\mathrm{O}$ 
autor defende que saúde é um aspecto integralizador, passível de aprendizado, que se dá ao longo de toda vida, desde a mais tenra idade no cotidiano intra e extraescolar. Segundo a cosmovisão de Rudolf Steiner, o ensino proposto nos moldes da Pedagogia Waldorf tem caráter sanativo (STEINER, 2008a). Nesse sentido, a proposta da Salutogênese, de Antonovsky (1997) encontra forte eco na maneira como a Pedagogia Waldorf tem de ver e viver a Educação.

A relevância em verificar como uma estrutura pedagógica pode, potencialmente, ser promotora de saúde está também pautada no incremento do adoecimento da população mundial. Segundo os documentos da Organização Mundial da Saúde, relativos às linhas mestras das macropolíticas orientadoras de promoção de saúde para o século XXI (GLÖCKLER, 2003), se continuarmos no mesmo ritmo, em 2100 seremos uma sociedade representada por apenas $20 \%$ da população com condições de saúde para trabalhar, enquanto $80 \%$ dependerão de assistência social. Outrossim, várias pesquisas apontam para a qualidade de vida e a menor incidência de doenças em ex-alunos Waldorf (ALM, 1999; ALFVÉN, 2006; MARTI; HEUSSER, 2009; HUECK, 2014).

A Pedagogia Waldorf é resultado das pesquisas do austríaco Rudolf Steiner (18611925), doutor em filosofia pela Universidade de Rostock, Alemanha. Convidado a compilar as observações científicas de Goethe no arquivo Goethe-Schiller em Weimar, Steiner, baseado nesses estudos, sistematizou uma nova ciência, a qual denominou Antroposofia, com a pretensão de integrar homem, natureza e cosmos, formatando novos modos de se organizar várias áreas do conhecimento, incluindo-se a Medicina, a Pedagogia, a Agricultura, a Astronomia, a Física, a Administração, as Artes, a Arquitetura etc.

A primeira Escola Waldorf nasceu em Stuttgart, Alemanha, em 1919. Atualmente essas escolas estão presentes nos cinco continentes com 1.056 escolas e, aproximadamente, 2.000 jardins de infância (denominação atribuída às escolas de Educação Infantil) em 61 países (WALDORF WORLD LIST, 2014). Stuttgart era, então, uma pequena cidade da Alemanha, destruída pela guerra. Era nesse espaço que nasceria uma escola, para filhos de funcionários de uma fábrica, com poucos alunos e recursos, mas, segundo Steiner, com as mais elevadas metas sociais, baseadas em fundamentos puramente pedagógico-didáticos. Segundo Steiner (2008a, p. 28): "A principal consequência do caminho trilhado pelo movimento antroposófico em suas várias fases foi o processo didático-pedagógico onde desembocou". 
No Brasil, a primeira Escola Waldorf foi implantada em São Paulo, em 1955, por um grupo de educadores, dentre eles, o pioneiro Rudolf Lanz, tradutor, incentivador e conferencista das obras de Rudolf Steiner, especialmente as que se referiam à Educação. A administração dessas escolas é do tipo autogestão, geralmente assumida por uma associação sem fins lucrativos, composta de pais e professores. Os pais têm uma participação intensa em todo o processo desenrolado nessas escolas.

A formação do professor Waldorf acontece nos chamados Seminários Pedagógicos (nome dado ao curso completo de formação, institucionalizado em todo o mundo). Segundo a Federação das Escolas Waldorf do Brasil (FEWB), são quatro anos de formação, 1.200 horas/aula e 400 horas de estágio supervisionado em escolas Waldorf. Na Alemanha, seguese a mesma estrutura, segundo informou o Seminar für Waldorf Padagogik Berlin.

\section{A Pedagogia Waldorf}

Ao sistematizar a Pedagogia Waldorf, a grande preocupação de Steiner é com a formação de um ser humano integral, desviando-o tanto quanto possível do impulso materialista (exclusivamente intelectual), segundo ele, potencialmente desumanizador que insiste em ganhar espaço tanto externa, quanto internamente no desenvolvimento humano (STEINER, 2008a). Sua proposta pedagógica encontra-se, no limite, com esse enfrentamento, insistindo em manter e promover um desenvolvimento humanizado que contemple a multidimensionalidade humana, construindo participativamente, sob a mesma egrégora, o desenvolvimento saudável dos educandos.

Se, por um lado, é perceptível o avanço da humanidade graças ao intelectualismo, por outro, ao se privilegiar na educação, exclusivamente o intelecto, corre-se um sério risco de patrocinar uma degeneração das forças realmente humanas. É justamente a arte da educação que requer um olhar para aquilo que define e distingue o ser humano dos outros seres vivos: sua porção anímica e espiritual correlata com a gênese dos impulsos morais, em certo sentido, especialmente na criança (STEINER, 2013).

Sabe-se que o ser humano, apesar de nascer com esse título, só se torna verdadeiramente humano, se aprender a ser humano - "nascemos humanos, mas isso não basta: temos também que chegar a sê-lo" (SAVATER, 2006, p. 29). As características humanas são despertadas por outros seres humanos. O eu humano ganha espaço e percepção no 
decorrer do crescimento; ele precisa de um modelo que o inspire e impulsione, daí a importância dos adultos que recebem, convivem e orientam esse pretendente a ser humano na construção de sua própria existência.

A Pedagogia Waldorf se diferencia não só por estar focada no indivíduo, mas por sua própria concepção; sua estrutura aponta para o conhecimento da integralidade humana, abrangendo os aspectos físico, anímico e espiritual, rumo a um desenvolvimento saudável. É necessário elucidar, em qual sentido se faz referência sobre espírito. Encontramos em Vaz (1991) indicações congruentes com a ideia steineriana expressa nesse texto. Diz o autor:

\begin{abstract}
Ao se elevar o homem ao nível do espírito, há que se anunciar a noção de espírito como coextensiva à noção de ser: de fato na estrutura espiritual ou noético-pneumática, o homem se abre enquanto inteligência (noûs), à amplitude da verdade; enquanto liberdade (pnêuma) à amplitude do bem; como espírito é o lugar do acolhimento da manifestação do ser. O espírito é, segundo a terminologia clássica, uma perfectio simplex em si mesmo, atualidade infinita do ser. Por isso mesmo, é pelo espírito que o homem participa do infinito. Portanto, é na sua estrutura espiritual ou noéticopneumática que o homem se mostra um ser de fronteira, passando por ele a linha de horizonte que divide o espírito e a matéria [segundo a comparação clássica que Tomás de Aquino tornou célebre] (VAZ, 1991, p. 202).
\end{abstract}

Para Steiner, o conhecimento do ser humano está ancorado no conhecimento do mundo. Entende-se desse pressuposto que a Educação está historicamente atrelada à visão e às ideias vigentes à época na qual se realiza e no conhecimento produzido por elas. Há também um forte apelo para que sejam percebidas e exploradas todas as potencialidades dos indivíduos e seu "vir a ser". Segundo o autor: "É preciso cuidado para, com coragem, buscar as origens das sensações e impulsos para se construir conhecimento do mundo, onde haja lugar para o ser humano em toda sua inteireza", revela Steiner (2008a, p. 31).

Por inteireza, ele estaria se referindo aos constituintes internos do ser humano que, além dos processos físico-químicos, inclui a estrutura anímica, que confere a possibilidade de se construir uma integração com a verdade, com as relações causais e a realidade, dirigindose a um desenvolvimento global, capaz de imprimir sentido à vida. No intelectualismo exagerado, como o praticado em alguns métodos pedagógicos ainda hoje, a base abstracionista regente poderá impedir a aproximação com o real, oferecendo um 'flutuar' do conhecimento que nunca consegue 'pousar' na realidade.

Essa condição, quando admitida, distancia-se do conhecimento do ser humano, não sendo suficiente para embasar uma pedagogia, pois "o relacionamento pedagógico e didático 
é necessariamente um relacionamento humano" (STEINER, 2008a, p. 41). Para o autor, como meta, "o que deveria ser a tarefa do educador, seria levar o aluno à livre utilização de sua corporalidade física, que se tornaria o substrato para a ação do anímico-espiritual” (p. 209).

Rudolf Steiner afirmou categoricamente que, por ser a Pedagogia Waldorf pura pedagogia, poderia adaptar-se a qualquer condição externa, de clima, de estrutura, de legislação, seja na cidade ou no campo. Segundo o autor, "ela não é moldada em condições específicas, e sim visa ao próprio ser humano em crescimento" (STEINER, 2013, p. 179). Essa proposta pedagógica, de acordo com Lanz (2000), se baseia no princípio de que qualquer cidadão independente de classe social, religião ou raça tem o direito a uma educação completa.

Há escolas Waldorf em vários países do mundo, organizando-se e adaptando-se às políticas e às suas diferenças culturais, porém com um mesmo fio condutor: a integralidade regida pelo desenvolvimento igualitário do Pensar, do Sentir e do Querer. Steiner, já em sua época, tentava evitar (pedagogicamente) todo tipo de "disciplinarização". Para ele, o ser humano é uma unidade e sua educação deve seguir seu desenvolvimento, que só pode acontecer sem fragmentações, sejam elas praticadas em qualquer âmbito da estrutura humana (STEINER, 2008a).

Assim como no organismo humano, não é possível manter a vida sem que haja uma interação orgânica (os pulmões dependem do coração, que depende dos rins e do fígado etc.). Da mesma forma, para aprender, o ser humano precisa acionar uma rede de relações e contextualizações que toque e/ou desperte sua realidade e, junto com ela, impulsione o interesse íntimo rumo à cognição. A proposta da interdisciplinaridade avança nesse sentido, visando à formação de um todo coerente, se percebemos a escola e os educandos como um 'organismo vivo' que não pode ser enquadrado em disciplinas estanques, que não conversam entre si.

Na conjectura global das escolas Waldorf, os professores, pais, médicos, funcionários, auxiliares, e pessoal administrativo se unem num objetivo comum: o melhor desenvolvimento individual dos educandos, concorrendo para um aprendizado flexível, congruente com a prontidão e com o ritmo deles, com vistas à criação de um ambiente saudável. Pratica-se a transdisciplinaridade na qual todos os participantes do processo de aprendizagem trabalham em função de um 'bem comum', ou seja, organizam-se em um espaço onde todos se 
comunicam com todos e participam de ações conjuntas, especialmente porque o ensino é feito em épocas nas quais todos os professores ligados àquela turma de alunos, procuram oferecer, dos mais variados pontos de vista, o mesmo tema, explorando-o com a maior abrangência possível, visando equalizar o tempo de ensino de determinado conteúdo e aperfeiçoar a concentração, gerando maior interesse e aproveitamento (LANZ, 2000).

Pode-se projetar uma relação do modus operandi da estrutura Waldorf com a Salutogênese quando este método busca adequar um fluxo saudável de atividades e conteúdos ao trabalhar com a realidade próxima dos educandos e com a disposição das próprias qualidades humanas como solidariedade, respeito, alteridade, responsabilidade, amorosidade, no sentido de um aprendizado que leve essa realidade a fazer sentido. Assim, ele viabiliza a significância. Quando persegue a clareza na busca da compreensão, institui a inteligibilidade e, quando estimula o fazer com as próprias mãos, demonstrando que a realidade pode ser manuseada, alça a característica da manuseabilidade - evidenciando os três componentes do Senso de Coerência, fio condutor da Salutogênese (ANTONOVSKY, 1997). Essa é a proposta da Pedagogia Waldorf que reconhece congruências com o conceito de Salutogênese de Antonovsky, como veremos a seguir.

\section{Salutogênese e o Senso de Coerência}

O conceito de Salutogênese ou novo paradigma em saúde, como preferem alguns, é uma proposta do sociólogo Aaron Antonovsky (1923-1994), elaborada a partir da década de 1960. Ela vem ganhando progressivamente espaços no campo da Saúde, especialmente nos lugares ocupados pelas posições das medicinas integrativas. A palavra Salutogênese tem, na sua etimologia, a junção da palavra latina "salus, salutis", que significa "saúde, bom estado, conservação" e "genesis", de origem grega, que quer dizer "origem, geração, criação". Portanto, salus + genesis = salutogênese (a origem da saúde), isto é, a busca das razões que levam alguém a se manter saudável.

Essa é uma concepção contrária ao paradigma hegemônico da Patogênese, dirigido para a origem das doenças, que se ocupa em saber o que causou determinada doença e em conhecer o agente causal, geralmente externo, que poderia ser uma bactéria, um vírus etc. A Salutogênese propõe novos questionamentos diante de estados de doença ou ausência dela: por que determinados indivíduos chegaram àquele distúrbio? Quais fatores biográficos 
contribuíram para se chegar àquela situação? Como indivíduos expostos aos mesmos mecanismos (guerras, catástrofes, epidemias etc.) não são afetados da mesma maneira?

Nesse percurso, a Salutogênese se serve do conceito de resiliência, que indica a potencial capacidade de se retornar ao estado próximo da normalidade após sofrer pressões dos mais variados níveis. Algumas pessoas parecem apresentar maior resistência diante de estados potencialmente estressores, lançando mão de uma série de recursos físicos e psíquicos, adquiridos por meio de aprendizados durante a vida. Esses saberes são colocados a serviço de uma 'mobilização ativa' (ANTONOVSKY, 1997), seja ela externa ou interna, que os protege, evitando que o estresse se transforme em doença. Outras pessoas, todavia, parecem não ter esses recursos disponíveis e, assim, não resistem.

Ao se indagar sobre recursos de resistência, coloca-se o foco na pessoa por inteiro (ou seja, na biografia, na história de vida do sujeito) e não somente nos sintomas, convergindo para o conceito de integralidade, que coincide com a proposta de ensino Waldorf. A Salutogênese propõe que se construam, graças a um aprendizado constante, recursos de resistência que se originam não só num projeto de autocultivo, de valores, de significados individuais e coletivos, que passam necessariamente pelo período escolar, mas também no acesso a Programas Sociais de Saúde Pública e Educação, juntamente com uma relação saudável com o ambiente, entre outras (MORAES, 2006).

Para Antonovsky (1979), Saúde não é um estado de homeostase (estável), mas, ao se confrontar com influências danosas, deve ser restaurada continuamente (heterostase); saúde e doença não são estados mutuamente exclusivos, mas polos extremos em uma conexão contínua (saudável/não saudável); nos intervalos, encontram-se estados de saúde e doença relativos. O autor propõe uma distinção entre tensão e estresse, conceituando a primeira reação como tensão psicológica, que pode evoluir para estresse, dependendo do valor dado ao estímulo e à capacidade de superação de cada indivíduo. A dimensão mais importante que determina o ápice dessas reações de valor e superação, como Antonovsky a entende, é por ele denominada de Senso de Coerência-Sense Of Coherence - S.O.C.

De um modo geral, o Senso de Coerência se refere à "habilidade, desenvolvida através das experiências de vida, em administrar uma série de atitudes em direção à resolução de conflitos ou potenciais estressores" (ANTONOVSKY, 1979, p. 27). Esse autor apresenta o Senso de Coerência com três características: Inteligibilidade, Manuseabilidade e Significância. 
Um fator central para a hipótese de os conceitos de Salutogênese e Pedagogia Waldorf estarem correlacionados, é o fato de haver uma correspondência entre esses três fatores e a visão trimembrada do sujeito, elaborada por Rudolf Steiner no início do século XX, a saber:

- esfera cognitiva - pensar - inteligibilidade (ou compreensibilidade)

- esfera afetiva - sentir - significância

- esfera volitiva - querer/agir - manuseabilidade

O Senso de Coerência não se relaciona com uma tipologia do ser humano. Antonovsky o considera como um tipo de "orientação disposicional" (MORAES, 2006, p. 28). É possível também imaginar um parentesco do Senso de Coerência com o que os filósofos alemães chamam de Lebensanschauung - 'visão da vida' ou 'visão de mundo', que indica que o aprendizado internalizado das experiências cria um centro de recursos, acionado em situação de estresse. Nesse sentido, uma pessoa com forte Senso de Coerência, tende a lidar de maneira satisfatória com estressores, ao contrário do indivíduo com Senso de Coerência fraco.

O Senso de Coerência é uma orientação global que expressa de maneira contínua, dinâmica, o sentimento de confiança de que: os estímulos derivados de ambientes internos e externos no decorrer de vida, sejam estruturados, previsíveis e explicáveis; recursos estão disponíveis para preencherem as necessidades exigidas por esses estímulos; essas exigências são desafios, que fazem sentido e valem o investimento e o comprometimento. Antonovsky propõe que quanto mais forte o Senso de Coerência do indivíduo, mais sucesso ele terá para se manter saudável (ANTONOVSKY, 1979, p. 19).

Segundo Antonovsky (1997), esse seria o fio condutor, considerado núcleo central da questão salutogenética. $\mathrm{O}$ autor assegura que todas as experiências positivas internalizadas detêm forças reais de superação e que a integridade física, psíquica e espiritual, cujo aprendizado se desenvolve ao longo de toda a vida, está atrelada à formatação do Senso de Coerência.

O Senso de Coerência constitui-se, portanto, do aprendizado cognitivo e emocional de toda a vida, incluindo-se o período escolar. É responsável por aquilatar e modular a maneira pela qual cada indivíduo responde a condições estressoras, ou seja, como cada pessoa aprende a lidar com seus problemas, segundo foi formada a qualidade de seu Senso de Coerência (MARASCA, 2017).

O conceito de Salutogênese ainda é relativamente novo, se considerarmos que a Patogênese, voltada à doença, ou ao agente causal, está em vigência há mais de três séculos. 
A Salutogênese tem ainda um caminho a ser percorrido, o qual não exclui necessariamente a Patogênese. Ao contrário, a associação de ambas poderia render uma profícua complementaridade, especialmente no campo da pesquisa. Após apresentação dos dois conceitos - Pedagogia Waldorf e Salutogênese -, indicamos, a seguir, algumas das bases epistemológicas que sustentam a Pedagogia Waldorf.

\section{Bases epistemológicas da Pedagogia Waldorf}

Derivada da Antroposofia, a Pedagogia Waldorf se regimenta com os mesmos pilares que sustentam esta filosofia. Cumpre evidenciarmos alguns deles, direcionados às questões de Educação e Saúde.

\section{A constituição quádrupla do ser humano}

Para se pensar o humano ou a condição humana, como diz Morin (2000), não se pode separá-lo de sua posição no mundo, ou seja, conhecer o humano é, antes de tudo, situá-lo no universo e não se separar dele. A educação do futuro deverá ser o ensino primeiro e universal, centrado na condição humana. Segundo o autor, "Todo conhecimento deve contextualizar seu objeto, para ser pertinente. Os progressos da cosmologia, da ecologia, da biologia, da préhistória nos anos 60-70, modificaram as ideias sobre o Universo, a Terra, a Vida e sobre o próprio homem" (p. 47).

Porém, parece haver ainda, uma dicotomia que se traduz, segundo Morin (2000, p. 48), num problema epistemológico:

[...] é impossível conceber a unidade complexa do ser humano pelo pensamento disjuntivo, que concebe nossa humanidade de maneira insular, fora do cosmos que a rodeia, da matéria física e do espírito ao qual somos constituídos, bem como pelo pensamento redutor, que restringe a unidade humana a um substrato puramente bio-anatômico.

Um dos fundamentos básicos oferecidos pela Antroposofia é a possibilidade de observar quatro diferentes fenômenos que, ainda que integrados no ser humano vivo, possuem natureza e expressões distintas: material (físico), vital (etérico), psíquico ou anímico (astral) e espiritual (Eu). Rudolf Steiner concebeu o homem atual como portador de quatro instâncias que representam a introjeção dos três reinos da natureza, mais o próprio Eu - o elemento distintivo da individualidade e da condição humana. Segundo ele, o ser humano pode ser apresentado como a própria evolução do universo, contendo em si todos os seus 
estágios precedentes e seus respectivos elementos representativos: o reino mineral $\rightarrow$ elemento terra (físico) - representado pelas 'substâncias' (Ca, K, Na, Fe etc.); o reino vegetal $\rightarrow$ elemento água (vital) - representado pelos 'processos' (crescimento, regeneração, reprodução etc.); o reino animal $\rightarrow$ elemento ar (psique - anímico) - representado pelas qualidades dos 'movimentos e sentimentos'; o elemento fogo (calor) representado no Eu humano (o espírito) - que confere as capacidades de autoconsciência, compreensão e elaboração de conceitos e também de renúncia (LANZ, 2000).

\section{A Trimembração: Pensar, Sentir e Querer}

Todo o desenvolvimento do sistema pedagógico Waldorf, incluindo suas práticas, está assegurado nos três pilares indicados por Rudolf Steiner como ordenadores do mundo interno ou psique: o Pensar, o Sentir e o Querer. Tais conceitos, impregnados da visão holística de Steiner, são fundamentais para a articulação e a compreensão da complexidade do desenvolvimento humano por ele proposto. Em sua obra Filosofia da Liberdade, Steiner (2008b), traça com profundidade reflexiva e crítica um percurso do desenvolvimento do Pensar humano como protagonista e orientador do 'si mesmo', organizando, simultaneamente, sua interação com o Sentir e o Querer.

\section{O Pensar}

Faz-se mister, introduzir essas concepções diretamente conectadas ao processo didático-pedagógico que inspiraram a Pedagogia Waldorf, especialmente no que se refere às atribuições do Pensar e suas derivações: a observação, a formação de conceitos, a cognição e a representação mental. Após esse percurso, ainda iluminados pela Filosofia da Liberdade, intentamos conjugar as relações entre Pensar, Sentir e Querer.

Para chegar ao conceito de observação, Steiner (2008b, p. 31) dá o seguinte exemplo:

[...] se eu me propuser a observar uma bola de bilhar que transmite seu movimento ao encontrar outra bola parada, constatarei que nada existe de mim, como observador nesse processo, se eu quiser apenas observar. Agora, se eu quiser refletir sobre o conteúdo de minha observação com respeito ao movimento da segunda bola, se de fato acontecer, essa observação vai na direção da formação de um conceito do que foi observado; esse sim, depende de mim.

Se o processo observado, em princípio, não depende do observador, o processo conceitual obriga a participação deste. Só a observação pura nada revela sobre o processo e 
suas conexões, as quais só aparecem quando se junta o Pensar, ou seja, quando há necessidade da formulação de conceitos, (atributo do Pensar), que exige a participação do indivíduo (STEINER, 2008b).

Ao olhar um objeto, a observação é estimulada; segue-se a isto o complemento do conceito. Quando o objeto sai do campo visual, o que permanece é o seu conceito. No entanto, é graças ao Pensar que se vincula ao todo, ao universal. Em virtude desse pensar universal, emerge em uma aspiração que supera a existência particular, incitando o desejo por cognição. Seres que não pensam não sentem esse desejo; o sujeito não pensa por ser sujeito, mas se identifica como sujeito porque é capaz de pensar (STEINER, 2008b).

A percepção é o resultado da observação; ao ampliar a percepção, obrigatoriamente são feitas correções de imagens de mundo que foram formadas anteriormente. A percepção do Eu pode estar acompanhada de outras percepções, ou seja, a percepção de um objeto me dá primeiro a consciência dele, porém, ao mesmo tempo, posso perceber meu próprio sujeito. Por exemplo: vejo a árvore e sei que sou eu quem vê a árvore; mesmo após o desaparecimento da árvore, permanece em mim uma imagem dela - a representação da árvore que vive no âmbito do meu sujeito (STEINER, 2008b).

A autopercepção se restringe ao si mesmo, mas o pensar está além deste limite. Nesse sentido, pode-se dizer que o pensar se relaciona com o mundo; ao contrário das sensações e dos sentimentos, que são particulares, o Pensar, é universal (se expressa nos conceitos). A percepção, portanto, é um dos lados; o outro lado é o conceito; juntos, os dois formam o ato cognitivo (STEINER, 2008b).

Uma observação sempre modifica o sujeito, pois, a partir dela, ele será capaz de reproduzir o objeto observado. Mesmo não havendo mais a presença do objeto, se é capaz de reproduzi-lo mentalmente: é a capacidade de representação mental. “A representação mental é uma representação subjetiva, diferente da representação objetiva, quando ainda se tem o objeto no horizonte de visão" (STEINER, 2008b, p. 74).

De um modo geral, o Pensar é a grande dádiva do ser humano. É ele que torna esse ser, o mais consciente de toda criação, dotando-o da capacidade singular de refletir sobre si mesmo e de ser passível de educação e realização. O Pensar pode se caracterizar de modo rígido, tendencioso, inflexível, se for, por exemplo, aportado em pessoas que consideram somente suas opiniões como válidas, não sendo capazes de abrir-se a opiniões diferentes da 
sua, constituindo-se em teimosos, bitolados (BÜHLER, 1987). Outras tantas situações desencadeadas pelo pensar podem promover distúrbios, que culminam nos mais diversos desequilíbrios da organização humana.

Um pensar ágil, adquirido na boa educação, na convivência social, nas convicções políticas, religiosas etc. pode experimentar a infinita capacidade de metamorfoses, permitindo, ao arbítrio individual, a configuração de cada uma delas. É plausível, antes de qualquer opinião, percorrer um caminho iluminado de possibilidades para qualquer assunto, interno ou externo, transitando por inúmeras situações e considerações, exercitando a elasticidade e a habilidade do pensar, dirigindo-se para o mais próximo possível do pensar organizado e realista. "Um pensar treinado desse modo pode assumir a coragem de refletir novamente a respeito de pensamentos já formados e abandoná-los se necessário, em busca de aprimoramento da verdade" (BÜHLER, 1987, p. 14).

Na Pedagogia Waldorf, esse aprendizado é exaustivamente treinado na primeira parte da aula (aula principal), apresentado pelos mais diversos ângulos, evidenciando, tacitamente, essas proposições com vistas ao exercício da plasticidade do pensar. Observando criticamente propostas, atividades e oportunidades de cada indivíduo, dependendo do modo como o pensar se constrói e das mazelas a que todo ser humano está exposto, o pensar pode ser, em maior ou menor dimensão, um gerador de angústias e pessimismos, com os mais diferentes rumos e consequências. O próprio pensar pode atuar no sentido de favorecer seu desenvolvimento ou gerar seu impedimento, podendo construir edifícios de imagens irreais que desembocam em profundos sofrimentos.

Ao contrário, a atividade do pensar, quando bem conduzida, pode deixar para trás a solidão interior e se lançar para a vida universal do mundo das ideias, o qual todos estão aptos a acessar (BÜHLER, 1987). Segundo o autor, apesar de únicos, somos convidados a mergulhar nesse universo da totalidade original que irradia forças salutares para nossa vida anímica, o que nos protege de incertezas geradas nos mais diferentes estados mentais. "Quando o ser humano consegue avançar na representação do Eu, como princípio criador interior, ele consolida-se como uma integralidade, gerando, dentre outras coisas, um substrato para a saúde" (p. 18). Sendo o pensamento base para o conhecimento e o autoconhecimento e, admitindo-se que a Educação pode participar ativamente de tal construção, destacamos a anuência e a responsabilidade dos educadores, no sentido de atentarem a modos vivos e 
atraentes de patrocinar tal desabrochar.

\section{O Sentir}

Se o ser humano se relacionasse apenas pelo pensar, tudo se resumiria em percepção, conceito e representação mental. Porém, isso não nos bastaria. Relacionamos o que percebemos com nosso Eu, cuja expressão está em nosso sentir, traduzido em prazer e desprazer (simpatia/antipatia). É por essa natureza dual, que podemos manifestar nossa condição humana, ou seja, "o pensar nos une ao universo; o sentir nos traz ao nosso mundo interno" (STEINER, 2008b, p. 80).

Somente a atividade do pensar nos tornaria pessoas indiferentes; só o reconhecimento do Eu também teria o mesmo fim. As duas condições nos propiciam reconhecer a nós mesmos (Pensar), sentindo nosso ser (Sentir), tornando-nos seres individuais, mas relacionando, continuamente, nossa existência com as coisas e seres que nos cercam (STEINER, 2008b). Para o autor, "Uma verdadeira individualidade será aquela que, com seus sentimentos, se elevar o máximo possível à região das ideias" (p. 80).

Cada indivíduo pensa a sua maneira os conceitos universais, dependendo de sua condição de vida, ou do potencial de percepção que a sociedade onde vive lhe oferece. Entretanto, cada um relaciona sentimentos de forma singular, quanto a sua qualidade e intensidade. Seria possível relacionar a atividade do pensar a uma vida puramente conceitual (lógica), se permanecêssemos o tempo todo no campo das ideias. Essa premissa poderia ser estendida, se rotulássemos essa atividade de cognição por onde se chegaria ao conhecimento. Porém, isso não é uma realidade. Nossas percepções são moduladas também pelos nossos sentimentos. Steiner, (2008b, p. 100) considera que "O sentimento está para o sujeito, como a percepção para o objeto".

\section{O Querer}

O Querer é a outra expressão da personalidade humana. Nesse processo, também ocorre uma percepção objetiva do mundo; contudo, sua universalidade só se realiza quando o Querer, por meio das ideias (Pensar), se relaciona aos aspectos do mundo.

O motivo para o Querer pode ser conceitual ou ser determinado por uma representação mental, a qual pode suscitar as mais variadas ações, dependendo de cada indivíduo. Isso mostra uma constituição particular, individualizada do Querer, denominada de “disposição caracterológica" que, segundo Eduard Von Hartmann (apud STEINER, 2008b, p. 
107), evidencia a qualidade singular do Querer.

De um modo geral, segundo Steiner (2008b), as leis morais estão incluídas na 'ação livre', pois há que se considerar que, mesmo havendo uma unicidade do mundo das ideias, este mundo é o mesmo 'gerador' de ideias, do qual todos fazem parte. A diferença está em como cada ser recebe suas próprias intuições, hauridas do mesmo gerador e as realiza, ou seja, torna-as sua realidade. Steiner (2008b, p. 116) pontua que "Viver em amor com as próprias ações e deixar viver em plena compreensão a vontade alheia, é a máxima dos homens livres".

Seria ingenuidade não considerar que a maioria das pessoas cumpre seus deveres obedecendo a leis morais. Seja por convenções ou impulsos, essa atitude ainda caracteriza um tipo de 'escravidão' à qual o homem livre não adere (STEINER, 2008b). É bem verdade que não se pode ser completamente livre em todas as ações. Porém, para Steiner, "verdadeiramente homens somos apenas como seres livres, ainda que a caminho desse ideal" (p. 117). Auxiliar o ser humano a buscar esse caminho, por meio do conhecimento (ato cognitivo), deve ser uma das metas da Educação.

A natureza faz do homem um mero ser natural; a sociedade, um ser que age conforme leis; um ser livre, somente ele pode fazer a si mesmo. Através das ações, o ser humano concretiza sua humanidade! A liberdade é a verdadeira meta de evolução humana, cabendo nesse caminho, inclusive ações concordantes com determinadas normas, desde que estas não assumam o papel de meta da evolução ética do ser humano (STEINER 2008b, p. 119).

\section{A correspondência Psicofisiológica da trimembração - pensar, sentir e querer}

Como objetivou Steiner (2013), a psique e o corpo físico se conjugam e se relacionam em três categorias:

a) a primeira categoria se relaciona com as imagens proporcionadas pelos órgãos sensoriais, os quais geram percepções e representações mentais a respeito dos conteúdos e, por fim, dos pensamentos advindos destas percepções e representações. Esses fenômenos são agrupados na categoria - Pensar - Sistema Neurossensorial.

Como essa atividade se processa de modo consciente, ela só se torna possível quando o ser humano está totalmente acordado. Nesse nível, é possível transportar os conteúdos do pensar para dentro da alma, ou seja, a alma tem a capacidade de fixar um conteúdo mental em seu horizonte e ficar, conscientemente submersa, no exame desse conteúdo (KALIKS, 
2015).

b) a outra categoria se relaciona com a manifestação de sentimentos, desejos, emoções, sensações, instintos - o Sentir - Sistema Rítmico.

Nessa categoria, os fenômenos se processam com menos clareza que no Pensar. Possuem aqui um caráter semiconsciente. Por vezes, não sabemos definir o porquê de um estado de tristeza ou de alegria. Reconhecemos o sentimento, mas não temos muita consciência de como ele se desenrola. Esses sentimentos e emoções, constantemente, são acompanhados de reações fisiológicas como transpiração, palidez, rubor, taquicardia etc., o que explicita a relação corpo e alma.

c) a terceira categoria é o Querer, a Vontade - Sistema Metabólico Motor.

Podemos dizer que essa é uma categoria que se revela praticamente inconsciente. Somente percebemos indícios de sua atuação, por exemplo, nos movimentos do corpo no espaço. Quando se 'quer' pegar algo, a mão vai executar o movimento em busca do objeto, porém, a pessoa não tem consciência de como esse ato se processa internamente. Assim como não se tem consciência daquilo que se passa no metabolismo, por exemplo, após a ingestão de qualquer alimento.

Como se vê, para Steiner (2013), o substrato corporal das funções da alma não tem sua sede unicamente no cérebro. Essas funções estariam distribuídas por todo o organismo, havendo regiões mais ou menos diferenciadas para cada atividade. Didaticamente, temos:

- O Sistema Neurossensorial cujo substrato é a cabeça (cérebro e órgãos dos sentidos);

- O Sistema Rítmico que está ancorado na região do tórax (pulmões e coração);

- O Sistema Metabólico Motor que está conectado à região do abdômen e dos membros.

Porém, há que se considerar que a trimembração anímica é um fenômeno funcional e dinâmico. Em todas as regiões orgânicas é possível constatar a interação dessas três atividades. Essa condição integralizadora é o que formata o principal objetivo do sistema pedagógico Waldorf, visando ao equilíbrio dessas três atividades, portadoras potenciais dos processos de saúde. 


\section{O Desenvolvimento Humano}

As teorias sobre o desenvolvimento humano, apesar de serem resultado de diferentes estudos e pesquisas validadas cientificamente, não se consolidam numa única teoria universalmente aceita, e nenhuma delas sozinha explica todas as suas facetas (PAPALIA; OLDS, 2000). Para Lievegoed (1991), a integralidade se realiza nas inter-relações entre o desenvolvimento biológico (físico), psicológico (anímico) e espiritual. Os desenvolvimentos psicológico e espiritual, têm seus padrões próprios e, juntamente com o biológico, influenciam-se reciprocamente. É nessa interação tríplice que a Antroposofia se baseia para definir a integralidade humana (BACH, 2007).

A Pedagogia Waldorf tem como característica básica conceber o desenvolvimento humano de forma global, integral, numa relação de reciprocidade e mutualidade entre corpo físico, psíquico e espiritual, que acontece em fases, a cada sete anos. Como já relacionado, Steiner (2013) propõe que os elementos constituintes do ser humano e do seu mundo interno estão distribuídos nas qualidades do Pensar (cognitivo), do Sentir (afetivo) e do Querer (volitivo), sendo que estas três forças, apesar de serem inerentes ao ser humano desde o nascimento, vão ganhando impulsos no decorrer das fases da vida e, segundo a qualidade do que é internalizado como aprendizado, é possível conquistar um desenvolvimento mais ou menos adequado.

\section{Os setênios}

É sabido que a vida humana vai muito além do caráter biológico, carregando em si outras instâncias que tornam a biografia de cada um uma história única, mesmo que regida por leis arquetípicas (PERLATTO, 2015). Cada ser humano percorre, com sua individualidade, um processo singular que imprime em suas experiências e seus propósitos.

Sabemos que o ser humano e sua instância espiritual difere dos outros reinos da natureza, sendo sua biografia conduzida por vários ritmos, destacando-se o ritmo de sete em sete anos, denominado por Rudolf Steiner de "Setênios" (LIEVEGOED, 1991). A cada sete anos, todos os seres humanos, em seu desenvolvimento adequado, passam pelas chamadas 'crises de desenvolvimento', o que já era também conhecido pelos gregos e pelos orientais. Tais crises podem ser entendidas como oportunidades de crescimento físico, anímico e espiritual, quando o desenvolvimento acontece de modo adequado.

Simplificadamente, temos a troca dos dentes em torno dos 7 anos, a consolidação da 
puberdade em torno dos 14 anos e a real maioridade aos 21 anos e assim sucessivamente. Atravessar essas 'crises' de maneira coerente, o que equivale dizer bem orientados e conduzidos pela família, pela escola etc., permite ao indivíduo viver uma vida saudável, o que não significa ausência de conflitos; pelo contrário, significa estar preparado da melhor forma para lidar com eles. Essa é uma das metas da Pedagogia Waldorf, reconhecendo que, embora presentes desde o nascimento, as três instâncias fundamentais do ser humano - corpo, alma, espírito - passam por evoluções ao longo de seu desenvolvimento biográfico (LIEVEGOED, 1991), a saber:

- Nos primeiros 21 anos, ocorre prioritariamente o desenvolvimento do corpo físico;

- Dos 21 aos 42 anos, são os níveis da alma que ganham maior desenvolvimento;

- Após os 42 anos, solidificam-se as questões essenciais, que habitam a instância espiritual do ser humano.

Como esses processos caminham juntos, nos primeiros 21 anos, os talentos, os dons ou as fraquezas podem ser amenizados ou exacerbados, pela educação que o indivíduo recebe. Nos 21 anos seguintes, deve ocorrer uma transformação daquilo que foi aprendido (no trabalho, na profissão, nas relações), ou seja, o indivíduo dá um significado singular àquilo que foi recebido pela educação. Isso se constitui na autoeducação. Após os 42 anos, as dificuldades podem se transformar em potencialidades, caracterizando um processo de autodesenvolvimento.

Uma biografia bem conduzida pode ser geradora/mantenedora de saúde, dependendo das escolhas feitas e da postura adquirida ao se relacionar com o mundo. É nesse encontro que o mundo criado internamente se relaciona com o mundo externo numa constante adaptação e flexibilização, o que, potencialmente, impede a presença de tensão, evitando a evolução para estresse e doença (ANTONOVSKY, 1997).

Na Educação, esse conhecimento é fundamental na condução dos ritmos e do respeito à prontidão, para que sejam oferecidos conteúdos e atividades de forma adequada, como proposto na Pedagogia Waldorf. Há que se considerar ainda a importância dos sentidos para o desenvolvimento sadio. Os sentidos são os órgãos de comunicação; são as "janelas" que colocam o mundo interno em contato com o mundo externo. Comandados pelo sistema nervoso, são eles que informam, paralelamente ao seu desenvolvimento, que o ser humano vai se tornando, passo a passo, um cidadão do mundo, por meio das percepções introjetadas, 
dia após dia, pela via sensória (MARASCA, 2015).

Tudo o que vemos, ouvimos, tocamos, experimentamos, exerce um reflexo físico (vitalidade dos órgãos) e um anímico (sensações e sentimentos) em nossa constituição. Os sentidos são as "antenas" que informam e, em certa medida, transformam nosso mundo interno, nosso modo de pensar, a qualidade do que sentimos e a força para impulsionar nosso querer, nossa vontade para agir.

Para Steiner (1997), o ser humano tem 12 sentidos a serem desenvolvidos: os sentidos básicos (tato, vital, movimento e equilíbrio); os sentidos intermediários (paladar, visão, térmico, olfato); os sentidos superiores (audição, sentido da palavra, sentido do pensamento, sentido do Eu), que ganham estruturação nos três primeiros setênios ( 0 a 21 anos), período quando acontece a base de toda a Educação. As principais características que precisam ser observadas, em cada setênio, como portadoras de um desenvolvimento sadio, segundo Treichler (1988), são:

- 1ํosetênio (0 a 7 anos) - Base para o amadurecimento físico. No primeiro setênio, a criança é totalmente aberta ao ambiente em que se encontra e está individualizando seu Querer. Nesse período, a educação deve se basear na realidade, na imitação, na fantasia e no ritmo. A criança espera se encontrar num mundo essencialmente bom. $\mathrm{O}$ ambiente precisa se prestar ao brincar, ao aprender fazendo, envolvendo coordenação motora, observação e socialização sem conceitualizações e/ou abstrações. "O professor nesse período deve ter um papel semelhante a uma 'mãe'” (LANZ, 2000, p. 213).

Com o nascimento, incorpora-se ao físico, o corpo etérico ou vital - portador dos processos e das transformações que geram vitalidade, com reflexos por toda vida. Toda base da saúde física é estruturada neste setênio; desenvolve-se todo metabolismo e seus respectivos órgãos, como o fígado, por exemplo, que tem forte influência na vontade, na espontaneidade, no Querer. Surgem também, a abertura, a confiança, a gratidão ao mundo e às pessoas; desencadeia-se a imitação de tudo e de todos: cores, formas, inclusive o caráter anímico. Acontece aqui o desenvolvimento dos sentidos básicos; é por meio dos sentidos que a criança 'sente' nessa fase da vida e essa qualidade irá compor toda a base do sentir do adulto. As doenças infantis são consideradas as crises de desenvolvimento desse período.

- 20 setênio (dos 7 aos 14 anos) - Base para o amadurecimento emocional. Nessa fase inicial da idade escolar, as forças vitais (etéricas) que se ocupavam do desenvolvimento físico 
no 1 으 setênio, passam a ficar disponíveis para o aprender. A troca dos dentes é um dos sinais externos dessa maturidade (prontidão). Esse período é marcado pela individualização do Sentir (sentimentos), acusando o despertar do corpo astral quando a criança espera encontrar um mundo belo - por isto a educação deverá ser pautada pela arte, pela estética. “O professor no 2 ㅇsetênio deverá ser um generalista" (LANZ, 2000, p. 214).

Nesse período, os sentimentos se dirigem e se concentram no tórax, onde permanecem (antes se encontravam disseminados pelo corpo todo). É importante que tudo tenha ritmo, como num processo respiratório: tarefas, descanso, atividades, artes etc.; o desenvolvimento privilegia o Sistema Rítmico: coração e pulmões. Nele nasce a proporção 4x1 (4 batimentos cardíacos para cada respiração). Essa é uma proporção saudável para os ritmos cardíaco e respiratório que se concretiza nesse 20 setênio, sendo essa aquisição diretamente proporcional aos ritmos vivenciados nos espaços intra e extraescolares. Fortalecem-se os sentidos intermediários.

- 3ำ setênio (dos 14 aos 21 anos) - Base para o amadurecimento social. Esse é o período em que o jovem começa a individualizar seu Pensar, evidenciando o aprofundamento do Eu, procurando por um mundo verdadeiro - só Ihe interessa a verdade. Nele o ensino deverá direcionar o pensamento abstrato para se apresentarem mais caracteristicamente os conceitos - a física, a química e seus experimentos nos laboratórios, por exemplo. "Os professores nesse setênio são especialistas" (LANZ, 2000, p. 215).

Nesse momento, os jovens se conectam com aquilo que thes revela a realidade, a verdade; é também quando se fortalece a relação com o outro. Há um desenvolvimento dos sentidos superiores. Aproxima-se cada vez mais o senso de responsabilidade e com ele também as dúvidas sobre as escolhas. É um período de reconhecimento do caráter moral do outro, inclusive dos professores, o que pode despertar o respeito. Nascem muitos ideais humanitários que precisam ser incentivados com trabalhos comunitários e filantrópicos aspectos observados na Pedagogia Waldorf.

É interessante perceber como o desenvolvimento humano vai integrando os processos corpóreos e anímicos, agregando os componentes da trimembração (Pensar/Sentir/Querer) e da quadrimembração (Físico/Vital/Psique/Eu) em tempos condizentes. Portanto, é fundamental que os educadores (pais e professores) estejam cientes dessa realidade para que, ao orientar seus alunos/filhos, consigam organizar um equilíbrio capaz de manter e 
promover saúde, no decorrer do desenvolvimento. Se houver aceleração ou desaceleração dos tempos e dos movimentos, pode acontecer de esses membros essenciais (etérico, anímico e espiritual) não serem implantados adequadamente, impedindo uma interação saudável destes, criando pré-disposições para futuras doenças (BURKHARD, 2016).

Portanto, há que se procurar o equilíbrio de acordo com a idade do aluno; respeitar os tempos de aprendizado de cada um, perceber o momento em que a atividade própria da criança abarca aquilo que se lhe quer ensinar; ministrar os conteúdos paulatinamente, segundo sua organização física e anímica lhe permitam. Por isso, o conhecimento do desenvolvimento das fases da infância, amparado pelo respeito às nuances individuais e do cotidiano, são aliados nos procedimentos práticos do educador Waldorf, visando à formação integral de seus alunos, incluindo-se sua saúde.

\section{0 ritmo}

Ritmo é a 'pedra de toque' da Pedagogia Waldorf. De um modo geral, podemos dizer que o ritmo se constitui de 'movimento e pausa'. Ritmo é ordem no tempo e, por isto, determinante para todos os processos funcionais saudáveis. A saúde está comprovadamente atada a uma ordem do ritmo das funções vitais. Distúrbios dessa ordem são frequentemente comprovados em casos de doenças (HILDEBRANDT; MOSER; LEHOFER, 1998).

No organismo, os processos se alternam ritmicamente, representados por anabolismo e catabolismo, ou seja, regeneração e desgaste, respectivamente. Eles nunca acontecem ao mesmo tempo, no mesmo sistema. Essa é a base do processo rítmico orgânico. Nesse sentido, estão relacionados também o sono e a vigília, em que o primeiro representa a pausa; o segundo, o movimento. A Ritmologia aponta para uma Psicofisiologia do desenvolvimento e é essencial no trabalho pedagógico para a vitalidade da criança (MARTI, 2003).

Considerando que existe um sistema rítmico, representado por coração e pulmões; que esses órgãos se desenvolvem paulatinamente durante a infância (especialmente no 2o setênio), e que são direta e proporcionalmente afetados pelas vivências rítmicas dos cuidados e das atividades dispensadas à criança, tem-se a dimensão da influência do ritmo no seu desenvolvimento saudável. A estruturação rítmica da aula, do dia, da semana e até das festas do ano, ou seja, uma construção consciente do ensino em bases rítmicas adequadas, tem papel importantíssimo na estruturação da vida/vitalidade das crianças.

Referimo-nos aos processos orgânico-psíquicos do amadurecimento saudável do ser 
humano, por meio do seu eixo condutor, o corpo etérico, que sofre alterações diretamente proporcionais ao ritmo de vida e de condições de aprendizado em crianças. Todo o cotidiano nas escolas Waldorf é orquestrado por ritmos, organizados de modo flexível, porém, de caráter imprescindível.

\section{A função da arte}

Para Steiner (2013), a arte é o campo de ação de médicos e professores. Tanto o curar, como o educar são processos artísticos. A arte na Pedagogia Waldorf se refere, em princípio, ao próprio método pedagógico: a arte da educação. Não se trata de um artifício para transformar conteúdos em processos palatáveis. É o próprio método que se revela artístico, na medida em que se apresenta de forma viva, moldando-se a situações com a maior originalidade possível; um processo sempre criativo, trazendo algo novo e individualizado.

Dessa maneira, não se estandartizam os procedimentos, de forma a serem reprodutíveis, com objetivos que miram resultados mensuráveis. $\mathrm{O}$ ensino de cunho artístico não é mensurável, como se avalia normalmente nas escolas tradicionais. Ele se orienta pelo "desabrochar criativo das possibilidades individuais" (MARTI, 2003, p. 10).

Para os professores, paralelamente ao conhecimento profundo da matéria, é necessária uma atuação sobre a fantasia, condizente com a situação e com a faixa etária. Fantasia, aqui, significa elevar a capacidade de se projetar estruturadamente para os processos do 'vir a ser'. A visão fenomenológica do desenvolvimento humano, descrita pela antroposofia, dá ênfase à possibilidade de a educação contribuir para o 'passar a ser o que ainda não se é' e não se atrelar ao passado (BACH, 2007).

A arte nas escolas Waldorf recebe uma atenção especial, por entender que seu papel é fundamental no desenvolvimento cognitivo, emocional e volitivo (ROMANELLI, 2010). Todos os processos de criatividade, resultantes das atividades relacionadas à arte, têm impacto na estruturação do corpo etérico (vital) das crianças, situação que se atrela diretamente à saúde das mesmas.

O cotidiano de uma Escola Waldorf permite observar a utilização de diversos procedimentos artísticos em sala de aula, durante toda a Educação Básica. Especialmente no período correspondente ao Ensino Fundamental, a pintura em aquarela e o uso de diversos tipos de narrativas - contos, mitos, biografias, norteiam a ação docente como base para o planejamento diário. 
Desde a alfabetização, uma narrativa pode subsidiar o ensino de qualquer conteúdo, como por exemplo o ensino da matemática ou da história. A pintura em aquarela é utilizada para a elaboração imagética dos conteúdos e perpassa todos eles ao longo da formação do aluno. Sendo assim, no currículo Waldorf, a arte está inserida desde a 'aula principal', que compreende as primeiras duas horas (em média) das atividades em sala de aula, quando são trabalhadas as esferas do Pensar, Sentir e Querer. Isso se explica por dois pressupostos teóricos tomados por Rudolf Steiner como fundamentação da Pedagogia Waldorf: "a cosmovisão Goetheanística, que propõe que se utilize a arte como metodologia para a aquisição de conhecimento; e a visão de Schiller sobre a necessidade de uma educação estética do homem" (ROMANELLI, 2010, p. 1).

Segundo Steiner (2013), é no período compreendido entre os anos do Ensino Fundamental e Médio que o desenvolvimento humano se abre para que se possa cultivar a sensibilidade e, desta forma, propiciar a aquisição de um equilíbrio das forças da fantasia e criatividade, com as forças da razão. Considera-se que o processo artístico leve o ser humano ao equilíbrio rítmico entre o Pensar, o Sentir e o Querer, organizando uma cooperação com os processos orgânico-psíquicos. Apresentamos aqui alguns dos pilares que embasam a Pedagogia Waldorf, bem como a Salutogênese, cujos arcabouços epistemológicos foram sinteticamente organizados, sem a pretensão de esgotá-los.

\section{Considerações Finais}

Certamente, a saúde do ser humano não está atrelada, unicamente, a sua educação formal. Dela, pode-se haurir um alicerce para a construção cotidiana e corresponsável para essa meta.

[...] saúde é o alicerce essencial que sustenta e alimenta o crescimento, a aprendizagem, o bem-estar pessoal, a satisfação social, o aumento de renda per capita, a produção econômica e a cidadania construtiva; trata-se do recurso natural fundamental de uma nação (ANTUNES; PERDICARIS, 2010, p. 11).

Saúde e educação são processos dinâmicos que se incorporam mutuamente exigindo uma mobilização para assegurar o desenvolvimento dos sujeitos.

Nosso objetivo foi apresentar dois conceitos - Pedagogia Waldorf e Salutogênese -, que convergem para os mesmos propósitos: a formação integral do ser humano, convocando 
sua multidimensionalidade. A formação integral, como apresentada, é um processo complexo que aciona, se bem dirigido, o autoconhecimento que pode permitir espaços para o conhecimento do outro, numa autoeducação permanente, concorrendo para a autonomia e o engajamento social.

O propósito de desenvolvimento da integralidade das dimensões humanas faz da Pedagogia Waldorf uma plataforma na qual a saúde pode evidenciar sua presença e abrangência nas atividades do cotidiano escolar. A coerência na sistematização dessa pedagogia tende a conduzir, especialmente por meio dos ritmos, não a um engessamento imposto por regras, mas à construção de uma ordem interna, o que leva os alunos a uma clareza dos tempos e dos movimentos, sustentando suas relações no fluir da vida, o que, provavelmente, evita processos de estresse.

O estado de tensão pode se originar da falta de compreensão ou de clareza daquilo que está sendo solicitado, impedindo a correta mobilização para ser bem-sucedido. O que se supõe é que, a partir da compreensão (inteligibilidade, pensar) daquilo que está sendo proposto, o passo seguinte é o movimento em direção à execução (manuseabilidade, fazer); assim, se consegue perceber um sentido (significância) para o que está sendo exposto e/ou proposto.

Dessa maneira, nas escolas Waldorf, parece haver um caminho coerente que se percorre até o resultado da tarefa. Essa organização interna, a nosso ver, base da segurança e da confiança, per se, portadoras de saúde, é trabalhada, pormenorizadamente, por meio dos instrumentos pedagógicos que guiam tal pedagogia.

Em última análise, pode-se inferir do exposto que Saúde e Educação se relacionam estreitamente com integralidade e coerência. Integralidade na Pedagogia Waldorf é vivência e realidade por meio da qual se constroem, igualitariamente, a compreensibilidade (Pensar), as capacidades de manejo (Querer) e de conferência de significados (Sentir), componentes de um movimento edificador de coerência, configurando-se, portanto, como uma educação potencialmente salutogênica.

Considera-se, assim, que o binômio saúde-educação pode regimentar uma unidade de caráter humanizador, intrinsecamente promotor de vida e saúde. Esperamos ter contribuído para suscitar, além do interesse pelos conceitos trazidos - Pedagogia Waldorf e Salutogênese -, uma reflexão sobre a possibilidade de a saúde poder, em seus mais variados aspectos, ser 
parte integrante do processo educativo, convidando outros métodos pedagógicos a cultivarem esta abrangência.

\section{Referências}

ALFVÉN, T. et al. Allergic diseases and atopic sensitization in children related to farming and anthroposophic lifestyle-the PARSIFAL study. Allergy, v. 61, n. 4, p. 414-21, 2006.

ALM, J. et al. Atopy in children of families with an anthroposophic lifestyle. Lancet, v. 353, n. 9163, p. 1485-1488, 1999.

ANTONOVSKY, A. Helth, stress and coping. San Francisco: Jossey-Bass, 1979.

ANTONOVSKY, A. Salutogênese: Zur Entmystifizierung der Gesundheit. Tubingen: DgvtVerlag, 1997.

ANTUNES, R.; PERDICARIS, A. Prevenção do câncer. Barueri, SP: Manole, 2010.

BACH, J. Educação ecológica por meio da estética na Pedagogia Waldorf. 2007. (Dissertação de Mestrado) - Programa de Pós-Graduação em Educação, Universidade Federal do Paraná, Curitiba, 2007.

BÜHLER, W. Forças curativas do pensar. In: BÜHLER, W. (ed.). Higiene social. São Paulo: Associação Beneficente Tobias, 1987. (Folheto 104).

BURKHARD, G. Tomar a vida nas próprias mãos. 6. ed. São Paulo: Antroposófica, 2016.

GLÖCKLER, M. Salutogênese: onde se encontram as fontes da saúde física, anímica e espiritual? Organização de Elaine Costa. São Paulo: Liga dos Usuários e Amigos da Arte Médica Ampliada, 2003.

HILDEBRANDT, G.; MOSER, M.; LEHOFER, M. Chronobiologie und Chronomedizin:

Biologische Rhythmen - medizinische Konsequenzen. Stuttgart: Hippokrates-Verlag, 1998.

HUECK, C. Salutogenese: gesundheitsfördernde Erziehungan Waldorfschulen. Blickpunkt Nr. 10. Bund der Freien Waldorfschulen: Hamburg, 2014.

KALIKS, B. A trimembração do organismo humano. Revista Humanum, São Paulo, v. 3, p. 7-9, 2015.

LANZ, R. A Pedagogia Waldorf: caminho para um ensino mais humano. 7. ed. São Paulo: Antroposófica, 2000.

LIEVEGOED, B. Fases da vida: crises e desenvolvimento da individualidade. 2. ed. São Paulo: Antroposófica, 1991.

MARASCA, E. Os doze sentidos. Revista Humanum. São Paulo, v. 3, p. 28-30, 2015.

MARASCA, E. Saúde na educação: indícios de congruências entre salutogênese e pedagogia Waldorf. 2017. Tese (Doutorado em Educação) - Universidade de Sorocaba, Sorocaba, SP, 2017. Disponível em: http://educacao.uniso.br/producaodiscente/teses/Teses_2017/elainemarasca.pdf. Acesso em: 02 set. 2018.

MARTI, T. Uma pedagogia que promove saúde. Federação das Escolas Waldorf no Brasil, $n$. 11, p. 6-17, out. 2003. 
MARTI, T.; HEUSSER, P. Gesundheit vier- bis achtjähriger Kinder vor dem Hintergrund des familiaren Lebensstils. Eine retrospektive Querschnittstudie an Kindern aus Schulen in der Stadt Bern und Umgebung. In: KULLAK-UBLICK, H. (ed.). Blickpunkt 10: Salutogenese gesundheitsfördernde Erziehung an Waldorfschulen. Bern: Bund der Freien Waldorfschulen Presse, 2009.

MINAYO, M. O desafio do conhecimento: pesquisa qualitativa em saúde. São Paulo: HucitecAbrasco, 1994.

MORAES, W. A. Salutogênese e auto-cultivo: uma abordagem interdisciplinar: sanidade, educação e qualidade de vida. Rio de Janeiro: Instituto Gaia, 2006.

MORIN, E. Os sete saberes necessários à educação do futuro. 2. ed. São Paulo: Cortez, 2000. PAPALIA, D.; OLDS, S. Desenvolvimento humano. Porto Alegre: Artmed, 2000.

PERLATTO, R. A biografia humana. Revista Humanum, São Paulo, v. 3, p. 10-11, 2015.

ROMANELLI, R. A arte como procedimento de ensino na Escola Waldorf. In: REUNIÃO ANUAL DA ANPED, 33, 2010, Caxambu. GT24. Caxambu: ANPED, 2010. Disponível em:

http://33reuniao.anped.org.br/33encontro/app/webroot/files/file/Trabalhos\%20em\%20PDF /GT24-6061--Int.pdf. Acesso em: 17 ago. 2016.

SAVATER, F. O valor de educar. Lisboa: Dom Quixote, 2006.

STEINER, R. Os doze sentidos e os sete processos vitais. São Paulo: Antroposófica, 1997.

STEINER, R. O desenvolvimento saudável do ser humano. São Paulo: FEWB, 2008a.

STEINER, R. A filosofia da liberdade: fundamentos para uma filosofia moderna. São Paulo: Antroposófica, 2008b.

STEINER, R. A prática pedagógica segundo o conhecimento científico espiritual do homem. São Paulo: Antroposófica - FEWB, 2013.

TREICHLER, R. Biografia e Psiqué: Graus, distúrbios e enfermidades da vida anímica. São Paulo: Melhoramentos, 1988.

VAZ, H. Antropologia filosófica I. São Paulo: Loyola, 1991.

WALDORF WORLD LIST. Freunde der Erziehungskunst Rudolf Steiners e.V, November, 2014. Disponível em: www.freunde-waldorf.de. Acesso em: 13 set. 2016.

Recebido em: 12/09/2018

Aceito em: 17/06/2019 